\title{
Assessing the Evidence Base on Health, Employability and the Labour Market - Lessons for Activation in the UK
}

\section{Colin Lindsay, Bent Greve, Ignazio Cabras, Nick Ellison and Stephen Kellett}

\section{Introduction}

Despite recent attempts by UK policymakers to restrict access to incapacity and disability benefits (DBs), ${ }^{1}$ claimant numbers remain high by historical comparison, with approximately 2.4 million people receiving these forms of income support in 2014. The need for policy action to assist people on DBs is not disputed. Spending long periods on these benefits has been associated with further deteriorations in health (Bambra 2011); the meagreness of payment rates in countries such as the UK means that claimants experience increased poverty risks (Kemp and Davidson 2010); and exclusion from work may undermine individuals' employability (Green and Shuttleworth 2013). However, there remain concerns that current policy agendas are not equal to the task of moving large numbers of people from DBs into sustainable employment. Indeed, the main focus of UK Government policy appears to be on restricting access to DBs by tightening eligibility criteria and meanstesting. There appears little sign of a coherent strategy to enhance the employability and health of those already on benefits (other than directing claimants to a generic, compulsory activation programme - The Work Programme - or other forms of 'work-related activity') (Lindsay and Houston 2013).

This article aims to offer direction on more productive foci for welfare reform and activation policies. We do this by reviewing the latest evidence on the 'nature of the problem' (i.e. the factors contributing to high levels of DBs among some groups and communities); analyzing

New Perspectives on Health, Disability, Welfare and the Labour Market, First Edition.

Edited by Colin Lindsay, Bent Greve, Ignazio Cabras, Nick Ellison and Stephen Kellett.

(C) 2015 John Wiley \& Sons, Ltd. Published 2015 by John Wiley \& Sons, Ltd. 
JWST632-co1 JWST632-Lindsay Printer:Yet to Come July 20, 2015 8:44 Trim: 229mm $\times 152 \mathrm{~mm}$

Colin Lindsay, Bent Greve, Ignazio Cabras, Nick Ellison and Stephen Kellett

the appropriateness of current and recent policies in responding to these factors; and (briefly) contrasting the UK's approach with that of Denmark, which has deployed a different set of policy instruments in its efforts to reduce DB numbers. In order to conduct this analysis of the nature of the problem and evaluation of policy solutions, we carried out a structured literature and evidence review identifying the most robust evidence from both academic sources and policy stakeholders. We used online search engines to identify key research and policy publications with keywords including 'activation', 'active labour market programme', 'incapacity benefits', 'disability benefits', 'welfare-to-work', and variants on these themes. Following a preliminary thematic review of outputs, we selected out key research reports and academic publications to provide the focus for our analysis because of their specific interest in the challenges, outcomes, benefits, limitations and lessons from employability programmes targeting those on DBs. The reliability of this approach was strengthened by its coverage of research from a range of disciplines (reflecting the multi-disciplinary expertise of the authors) including economic geography, social policy, clinical psychology and public health policy analysis. Our findings are presented below. The analysis also draws on the latest research published in this Special Issue of Social Policy $\mathcal{E}^{\circ}$ Administration. The article then concludes with a discussion of implications for future policy development.

\section{Assessing the Evidence Base: Factors behind Concentrations of Disability Claiming}

Over the past decade, successive UK Governments have deployed relatively consistent policies to address high levels of DB claiming. The focus of policy has been on restricting access to, and increasing the conditionality associated with, welfare benefits, along with a greater emphasis on activation, first under the Pathways to Work (PtW) initiative (2003-10) and now the Work Programme, the main activation programme for people of working age. However, it has been suggested that the general thrust of policy fails to address the complex combination of factors that explain concentrations of $\mathrm{dB}$ claiming (Beatty et al. 2009). Following Lindsay's and Houston's (2013) line of argument, we now assess the latest evidence on the extent to which three key issues can be identified as underlying the high level of DBs claiming in the UK, namely: concentrations of health and disability-related barriers among the claimant group; gaps in their employability and skills; and labour market inequalities and the impact of low quality work on opportunities for people with health and disability-related limitations. We then go on to discuss the failure of policymakers to develop joined-up, spatially-focused solutions to these problems.

\section{Health and disability-related barriers}

One of the distinctive features of the discourse around DBs in the UK is policymakers' reluctance to fully acknowledge that those claiming 
JWST632-co 1 JWST632-Lindsay Printer:Yet to Come July 20, $2015 \quad 8: 44 \quad$ Trim: $229 \mathrm{~mm} \times 15^{2 \mathrm{~mm}}$

Assessing the Evidence Base on Health, Employability and the Labour Market

these benefits are, indeed, sick or disabled. Policymakers partly justified this position with reference to a well-established evidence base suggesting that industrial restructuring and job destruction in regions dependent on traditional employment sectors preceded increases in DB claiming. Seminal works during the mid-1 990 os by Beatty and Fothergill (1994) and Green (1994) identified concentrations of DB growth in post-industrial labour markets, suggesting that Incapacity Benefit (IB, then the main DB) was absorbing displaced workers and hiding the real level of unemployment. These authors wished to expose the 'hidden unemployment' problem in order to demonstrate the need for regional demand-side policies to generate more job opportunities for those trapped on benefits (Beatty et al. 2000), but their argument has been appropriated by the political right as evidence of malingering (CSJ 2009).

Yet this is a misrepresentation of both the evidence and the argument. Indeed, Beatty et al.'s (2000, 2009) seminal 'theory of employment, unemployment and sickness' hypothesized that 'hidden sickness' was as important as 'hidden unemployment' in explaining high disability claiming in some regions. They argued that there is substantial illhealth and work-limiting disability throughout the labour force-among those in work, jobseekers who are available for work, and those receiving DBs. Labour market conditions decide whether those with health or disability-related barriers are able to find their way into work (due to employers' willingness to adjust their demands in tight labour markets) and manage their conditions in the workplace. But this need not lead us to conclude those on DBs are feigning illness.

Rather, there is substantial evidence as to the reality of the health and disability-related problems faced by people claiming DBs. Ill-health or limiting disability is consistently found as the primary reason why most DB claimants exit work in the first place, with extant health conditions then also a key barrier to return to work (Beatty et al. 2010; Kemp and Davidson 2010). Claimants with multiple and/or more serious conditions are significantly more likely to be 'permanently sick' (i.e. remain on benefits), in contrast to those with fewer conditions who are more likely to find work (Barnes and Sissons 2013). For those re-entering employment following a period on DB, but then failing to sustain work, a decline in health is a common feature (Dixon and Warrener 2008). Large-scale national population surveys such as the British Household Panel Survey (BHPS) suggest robust and long-term relationships between health and exclusion from work (Jones et al. 2010), although as noted elsewhere in this Special Issue these data also highlight the importance of interactions between ill-health and spatial labour demand inequalities (Whittaker and Sutton 2015). Robroek et al.'s (2013) analysis of older workers' trajectories in 11 countries based on the 'Survey of Health, Ageing, and Retirement in Europe' confirms that poor health and health behaviours as well as other work-related factors may all play a role in exits from paid employment, although their significance may vary according to exit routes. There is a significant 
JWST632-co1 JWST632-Lindsay Printer:Yet to Come July 20, 2015 8:44 Trim: 229mm $\times 152 \mathrm{~mm}$

Colin Lindsay, Bent Greve, Ignazio Cabras, Nick Ellison and Stephen Kellett

relationship between DB claiming and physical (Bambra 2011) and psychiatric mortality (McKee-Ryan et al. 2005).

National Health Service (NHS) professionals working with DB claimants confirm evidence of a broad range of interacting and comorbid health problems and disabilities (Lindsay and Dutton 2013). Other researchers have similarly used accepted clinical tools (such as the 'Hospital Anxiety and Depression Scale') to identify significantly poorer health among the DB claimant population that appears resistant to increasing exposure to conditionality and/or 'incentives' as part of changes to the benefits system (Garthwaite et al. 2014). Purdie and Kellett $(2015)$ evidence the pre-treatment severity of health problems and also register rates of associated clinically significant improvements following interventions to enable claimants to better manage their conditions. However, Rick et al. (2008) note that there are few well supported conclusions that can be made concerning the efficacy of health interventions to help DB recipients return to work, because the extant studies lacked credible outcome methodologies. Therefore, more methodologically robust outcome studies of health interventions with distressed claimants need to be conducted, in order to enable further meta-analytic perspectives to be taken. In summary, there is powerful evidence that health and disability-related limitations reported by those on DBs are real and an ongoing aspect of life without work. As we confirm below, other factors - and crucially the nature and extent of labour demand - tend to define whether such health and disability-related barriers can be managed in the workplace, or alternatively exclude people from the world of work.

\section{Employability-related barriers}

We see above that, contrary to some policymakers' claims, health and disability-related barriers are key to understanding the nature of the DB problem. Yet, successive UK Governments have been keener to portray the problem as rooted in the attitudes and behaviour of claimants. As we see below, increased conditionality and compulsion in the DB system appear to reflect a consensus among policymakers on the need to use financial incentives and punitive sanctions 'to generate positive behavioural effects' (DWP 2010: 10). From a behavioural theory point of view, policymakers rely heavily (or exclusively) on punishment, as opposed to reward contingencies, as a means of changing the work behaviours of DB claimants.

The evidence for the existence of a 'dependency culture' among DB claimants is, however, limited. Beatty et al.'s (2010) extensive survey research with DB claimants deployed a raft of attitudinal questions to assess work beliefs and found little evidence for negative or low levels of work commitment. Nor were DB claimants expert in 'playing the system (i.e. particularly knowledgeable about benefit regulations). Such findings enhance a long-established evidence base contradicting the rhetoric of individual claimants 'choosing to live on benefits' and 
JWST632-co 1 JWST632-Lindsay Printer:Yet to Come July 20, $2015 \quad 8: 44 \quad$ Trim: $229 \mathrm{~mm} \times 15^{2 \mathrm{~mm}}$

Assessing the Evidence Base on Health, Employability and the Labour Market

popular myths of families defined and populated by multiple generations of the unemployed (Shildrick et al. 2012). Rather, evidence from in-depth research with DB claimants finds recurring themes of poverty and insecurity whilst struggling financially to survive on benefits, with experiences of the benefits system (and especially increasing conditionality) defined by stigma and distress (Garthwaite et al. 2014).

That said, people on DBs tend to hold a variety of views about work. Green and Shuttleworth (2013) found that a range of factors (most notably age and health) shape claimants' optimism and level of commitment to work. Kemp's and Davidson's (2010) longitudinal research similarly identified differences in levels of work commitment amongst the DB group, although other variables related to health and employability were much more powerful predictors of individuals' chances of returning to the labour market. Webster et al. (2013) argue that perceptions of the severity of limitations imposed by health conditions and the state of the local labour market can interact to produce pessimistic self-evaluations of both health and employability.

So attitudes to work vary considerably - but there is limited evidence that individual motivation or commitment are decisive in explaining the significant labour market exclusion experienced by those on DBs. Nevertheless, there is stronger evidence that long-term DB claimants face a complex range of other employability-related barriers to work. Extensive survey work with those on DBs demonstrates that they are significantly more likely to report basic skills problems, low levels of qualification, gaps in work experience, repeated periods of unemployment and limited social network ties to those in work (Beatty et al. 2010, 2013; Green and Shuttleworth 2013; Kemp and Davidson 2010; Barnes and Sissons 2013). Garthwaite's (2015) research in this Special Issue provides compelling additional evidence of experiences of social isolation and poverty among DB claimants.

Such toxic combinations of employability-related barriers are common among people excluded from the labour market for long periods, and call for holistic activation programmes that are flexible in addressing the complex problems faced by disadvantaged groups. Indeed, the manner in which people on DBs often report multiple barriers and find themselves at the back of the queue for jobs means that supply-side activation is justified (Beatty and Fothergill 2015) - we simply dispute the appropriateness and capacity of current policy content to address the complex needs of many DB claimants.

\section{Labour market barriers}

Successive UK governments have been reluctant to acknowledge the spatial labour market inequalities that clearly shape the nature of the DB problem (Lindsay and Houston 2013). Yet, the evidence suggests that labour market inequalities are fundamental to explaining why people in certain communities are more likely to find themselves trapped on DBs. Beatty et al. (2000, 2009, 2010, 2013) have amassed a compelling 
JWST632-co1 JWST632-Lindsay Printer:Yet to Come July 20, 2015 8:44 Trim: 229mm $\times 152 \mathrm{~mm}$

Colin Lindsay, Bent Greve, Ignazio Cabras, Nick Ellison and Stephen Kellett

evidence base demonstrating that DB claiming is concentrated in those regional labour markets that experienced large-scale job destruction following industrial restructuring. In post-industrial cities, the processes of job destruction associated with the decline of manufacturing were never fully reversed during the 'long boom' of the 1990 and 20oos, which produced uneven growth, often in casualized and low-paid service work (Webster et al. 2013). In mapping DB claiming both before and after the Employment Support Allowance (ESA) reform in the UK, Lindsay and Houston (201 1:707) similarly conclude that 'the map of claim rates corresponds to areas of former industrial decline'. There is nothing particularly distinctive about DB claimants in post-industrial labour markets, there are just many more of them (Webster et al. 2013). This is explained by the lack of jobs to absorb people who otherwise might be able to cope with their health conditions in the workplace. In times of 'full employment', employers adapt their expectations so that people with health and disability-related limitations are more likely to find work (Beatty et al. 2013).

Employers and jobs may be of broader importance in understanding the DB problem. First, employers' willingness to make necessary and/or indicated adjustments to acknowledge health limitations - such as altering job content or work environment, or allowing changes to working hours or phased returns to work - can be crucial in facilitating re-integration for people on DBs (Kemp and Davidson 2010). Claimants regularly cite the identification of a 'sympathetic employer' as central in return to work planning (Green and Shuttleworth 2010: 234). However, lower-skilled workers in poor quality jobs in particular may struggle to negotiate adjustments with their employers (Baumberg 2015), with some employers, instead, seeming more likely to target those with health limitations for redundancy (Easterlow and Smith 2003). Increasingly aggressive absence management policies may also exacerbate health conditions among existing employees, while militating against a culture of adjustment and inclusiveness that might assist those returning to work (Taylor et al. 2010).

The nature and quality of jobs may also negatively impact opportunities open to people with health and disability-related limitations. As noted above, post-industrial labour markets may not have enough jobs to absorb people with health problems who could, nevertheless, manage some work. Low quality jobs in these labour markets may also contribute to the DB problem and throw up barriers to work for claimants. For example, DB claiming is more likely in labour markets dominated by casualized and short-term employment, where employers can more easily 'manage out' employees with health problems (Beatty et al. 2009). More specifically, under-employment (where employees are unable to secure sufficient hours or pay) may feed into the DB problem. Low-paid, part-time employees whose wages fail to meet the minimum National Insurance threshold are ineligible for employer-paid Statutory Sick Pay and are therefore more vulnerable to exit work in order to claim DBs. For people at the bottom of a polarized labour market, the benefits 
JWST632-co 1 JWST632-Lindsay Printer:Yet to Come July 20, $2015 \quad 8: 44 \quad$ Trim: $229 \mathrm{~mm} \times 15^{2 \mathrm{~mm}}$

Assessing the Evidence Base on Health, Employability and the Labour Market

system is therefore "working as a functional equivalent of sick pay (Kemp and Davidson 2009: 598).

The nature of the working life in poor quality jobs is also relevant. Claims that low-paid, entry level positions remain a stepping stone to better jobs appear contradicted by 'cycling' between work and repeated benefit claiming (Barnes and Sissons 2013). Meanwhile, in workplaces that are intensified and 'lean' or where employees have little control over the standard operating procedures that define how and where they work, there may be less scope to effectively manage health conditions and stay in work (Carter et al. 2013). For example, work governed by 'zero hours' contracts offers little structure around which necessary health behaviours could be planned and enacted. Baumberg's (2014) research - modelling a combination of health variables drawn from the BHPS and job content data from skills surveys - presents compelling evidence that a decreasing sense of control among employees over the past two decades has contributed to ill-health and potentially higher levels of disability claiming. There are few spatial studies quantifying the impact of changing quality across different regional economies, but we might therefore hypothesize that the dominance of low quality jobs in postindustrial labour markets (Shildrick et al. 2012) could be an additional factor contributing to concentrations of DB.

As Patrick (2012: 313) concludes, sick and disabled people seeking to return to work 'face a range of demand-side barriers, including the impact of stigma and discrimination, physical challenges around access and transport, and issues around the availability of suitably flexible job opportunities'. Our review of evidence above adds substantially to the evidence on this final point, demonstrating that the labour market inequalities - reflected in spatial differences in both the quantity and quality of jobs - may be crucial in shaping individuals' capacity to cope with health problems or disability in the workplace.

In summary, the most recent literature, including research presented elsewhere in this Special Issue, adds to the evidence that a complex combination of factors have combined to produce concentrations of DB claiming in disadvantaged labour markets and communities. Some of these factors reflect individual barriers, but there is little evidence that these can be simplified into a dependency culture that can be addressed through punitive welfare reforms or behavioural interventions. Rather, a combination of health/disability limitations and employability-related barriers to work combine to leave some people at the back of the queue for jobs. This disadvantage is exacerbated in post-industrial labour markets where there are not enough opportunities, and where the jobs that are available represent a difficult context within which to manage conditions (and in some cases may contribute to ill-health). A coherent strategy to provide routes into sustainable employment for people on DBs will therefore require: a range of employability-related services; integrated condition management provision to assist claimants to cope with health and disability-related limitations; and spatially-focused economic development and workplace strategies designed to ensure that there are 
JWST632-co1 JWST632-Lindsay Printer:Yet to Come July 20, 2015 8:44 Trim: 229mm $\times 152 \mathrm{~mm}$

Colin Lindsay, Bent Greve, Ignazio Cabras, Nick Ellison and Stephen Kellett

viable job opportunities for those leaving welfare to enter work. As we see below, the current UK policy agenda falls well short of meeting these demands.

\section{Assessing the Policy Agenda: Welfare-to-Work for People on Disability Benefits in the UK and Lessons from Abroad}

Current policy in the UK

To what extent is the evidence presented above reflected in the UK policy agenda on helping people from DBs into work? The current policy agenda demonstrates clear continuity with work-first approaches to activation. Within such approaches, the nature of the problem is seen as mainly rooted in the individual's attitudes and behaviour, with the logical conclusion that strengthening conditionality and compulsory activation can effect positive change in and for the individual (Lindsay and Dutton 2013). The replacement of IB with ESA as the main DB for new claimants from 2008 reflected these priorities. The ESA reform restricted access to the most generous benefit replacement rates to only those assessed as facing severe health/disability barriers, who are placed into a 'Support Group'. Those assessed as less disadvantaged are placed into a 'Work-related Activity Group' where receipt of ESA is conditional on engaging in work-focused interviews and other activation provision (see discussion below). Unlike its predecessor IB, ESA's contributionbased benefit is limited to one year for the Work-related Activity Group. Those still claiming ESA after this duration are required to transfer to a means-tested version of the benefit (meaning that those with other sources of household income may be denied payment).

Central to the ESA reform was the establishment of a stricter medical assessment - the Work Capability Assessment (WCA) - as a means of determining benefit entitlement. The WCA was introduced for all new ESA claimants by the Labour Government. The Conservative-led coalition Government then committed to re-assessing all existing benefit recipients from 2011; and there is also the expectation that all ESA claimants will be repeatedly re-assessed within two years (previously, IB claimants often reported several years between benefit eligibility assessments) (Harris and Rahilly 2011). As noted above, the WCA has been designed to separate the most disadvantaged, who are directed to the Support Group and receive DBs without condition, from those who might be able to make progress towards employment and are subject to compulsory activation - the Work-related Activity Group. The measures of work capacity deployed in the WCA process explicitly sought to 'raise the bar' in order to restrict access to benefits (for a detailed discussion of WCA content and scoring, see Harris and Rahilly 2011 ). Government clearly communicated that its expectation was that only a small minority of claimants should be directed towards the unconditional Support Group, and in its first year of operation the WCA found only 10 per cent of claimants to be so sick or disabled as to justify this status; 24 per cent 
JWST632-co 1 JWST632-Lindsay Printer:Yet to Come July 20, $2015 \quad 8: 44 \quad$ Trim: $229 \mathrm{~mm} \times 15^{2 \mathrm{~mm}}$

Assessing the Evidence Base on Health, Employability and the Labour Market

of claimants were directed to the Work-related Activity Group; and 66 per cent were judged fit for work and denied ESA.

Initial independent reviews confirmed the inadequacy of the WCA process, which was assessed as 'mechanistic', 'lacking empathy' and impractical in capturing the impacts of many chronic and/or mental health conditions (Harrington 2010: 31). These processes created the paradoxical risk of the stress of WCA creating mental health problems (and associated costs elsewhere in the health economy) or that DB claimants would become more resistant to health interventions for fear that responsivity would be taken as a prompt by WCA assessors to change their benefit status. Many claimants have been able to reverse WCA decisions on appeal (Patrick 2012), and more recent data suggests that the WCA is being applied more sensitively, probably in response to the high numbers of successful appeals.

The second, inter-connected element of the current UK model involves extending the reach of compulsory activation to many of those on DBs. The first major activation programme targeting disability claimants was PtW, piloted by the Labour Government from 2003 and rolled out fully by 2008. The initiative was initially led by Jobcentre Plus, with health-oriented condition management services organized by partner NHS organizations. As PtW was rolled out nationally, leadership of the initiative was contracted out to (mainly private sector) 'Lead Providers' in most regions, which saw the condition management component quickly marginalized within programme content (Lindsay and Dutton 2013). The main content of PtW instead centred on five compulsory work-focused interviews; and a range of voluntary work preparation programmes based on existing 'work-first' activation provision. Attendance at work-focused interviews was enforced via the threat of benefit sanctions. Condition management provision was more fragmented in those areas where PtW was led by contracted providers, which were not required to work with NHS organizations to develop health-focused interventions (Grant 2013). Overall, the national outcomes delivered by PtW were disappointing, with no significant employment effect associated with claimants' participation (NAO 2010). However, where regions had effectively integrated Department for Work and Pensions (DWP) and NHS provision to support return to work for DB claimants, the health and employment outcomes were significant (Kellett et al. 2011; Purdie and Kellett 2015).

From 2011, PtW and all other UK Government activation programmes were amalgamated within the Work Programme, led by multiple 'Prime Contractors'. A 'black box' funding model affords Prime Contractors considerable autonomy in shaping services, although a payment-by-results regime that offers limited up-front funding means that there is an incentive to target 'quick wins' through work-first interventions (such as short, relatively inexpensive motivational and job search courses). Accordingly, there is substantial evidence of 'creaming and parking' among Work Programme activation providers charged with improving the employability of those on DBs (HoC 2013). The 
JWST632-co1 JWST632-Lindsay Printer:Yet to Come July 20, 2015 8:44 Trim: 229mm $\times 152 \mathrm{~mm}$

Colin Lindsay, Bent Greve, Ignazio Cabras, Nick Ellison and Stephen Kellett

meagre health-focused provision supported under PtW appears to have been further marginalized, with few Work Programme providers prioritizing condition management. At the strategic level, there is limited evidence of engagement between the DWP and the Department of Health (Ceolta-Smith et al. 2015). The severity of the barriers faced by many claimants, the inadequate and inappropriate funding model for the Work Programme, and the resulting 'parking' of those with health/disability-related limitations, help to explain the disappointing job outcome figures achieved by the programme for people on ESA (Rees et al. 2014).

It is important to note that compulsion and conditionality remain crucial components of the Work Programme's interaction with the sick and disabled (and also defines other work-related activities that can be demanded of ESA claimants). Failure to engage in work-related activity required by Work Programme providers can result in a loss of benefits for four weeks for a first offence, rising to 13 weeks for repeated non-compliance (HoC 2013). However, there is evidence that advisers working for both Jobcentre Plus and Work Programme providers have been reluctant to report 'misbehaviour' that would result in sanctions these street-level professionals appear to be aware of both the vulnerability of many DB claimants, and that sanctioning is likely to undermine attempts to build a relationship of trust between claimant and adviser. Consequently, under both the Work Programme and its predecessor PtW, sanction rates have been relatively low (Grant 2013).

In summary, a narrow work-first focus defines current activation strategies for people on DBs. Policymakers remain reluctant to programme health provision as a central element of their approach, despite evidence as to the substantial health and disability-related limitations faced by claimants. Nor is there evidence of government interest in the role of employers - or the broader labour demand - in shaping the DB problem. It is perhaps unsurprising then that the outcomes produced by the UK Government's focus on conditionality and activation have been disappointing. As noted above, while increasing the conditions required both to access and receive benefits may reduce on-flow, there will be little progress in terms of improving people's employability or health. Yet we know from the review of evidence above, and analyses of the characteristics of returners-to-work, that improving employability and health are both key to positive transitions for DB claimants, and that labour market and workplace factors define the opportunities available to them (Barnes and Sissons 2013). We now turn to evidence from a very different welfare state - Denmark - in an attempt to identify any additional lessons that can be learned from its policy and practice in seeking to assist the sick and disabled from welfare to work.

\section{Lessons from abroad: current policy in Denmark}

There are a number of reasons why Denmark represents a particularly interesting counterpoint to the UK's experience. Like the UK, Denmark 
JWST632-co 1 JWST632-Lindsay Printer:Yet to Come July 20, $2015 \quad 8: 44 \quad$ Trim: $229 \mathrm{~mm} \times 15^{2 \mathrm{~mm}}$

Assessing the Evidence Base on Health, Employability and the Labour Market

is often seen as in the vanguard of 'activating' European welfare states. Denmark has also grappled with high levels of DB claiming in recent years. Yet, the Danish context is clearly distinctive from the UK in some respects. Denmark's social-democratic welfare traditions are reflected in benefits that generally deliver substantially higher replacement rates than are enjoyed by disability claimants in the UK. Denmark's spending on active measures (as a percentage of gross domestic product) is the highest in the Organisation for Economic Co-operation and Development; the UK's is in the bottom third, and the lowest of any major EU economy (OECD 2013). Furthermore, while Denmark has seen some moves towards marketization in activation (Lindsay and McQuaid 2009), there is not the same private sector dominance of service delivery, and local institutions continue to facilitate a role for social partner representatives in the policy process.

As noted above, Denmark's DB claim rate has been, and remains, relatively high, with increasing reporting of mental health problems contributing to consistently large numbers claiming (OECD 2011). The Danish policy agenda has been quite different from that pursued in the UK, although large-scale positive outcomes have similarly proved elusive. Recent policies have sought to raise awareness among disability claimants of the numerous instruments available to support labour market integration (Kjeldsen et al. 2013). But while there are signs that recent initiatives have successfully extended the reach of activation, for example to people with mental health problems, transitions into the mainstream labour market have proved difficult to achieve. There has been a decline in the number of people on DBs since 2011, with changes to the benefit system since 2013 further restricting access and therefore on-flow. These changes have meant that those below the age of 40 cannot claim the main 'permanent' DB (except for the most severely disabled with no prospect of developing their capacity for paid work). Most claimants under 40 are, instead, required to participate in so-called 'ressourceforløb' activation activities (as are those over 40 who have not previously undertaken such activities, in order to be eligible for DBs). During participation in ressourceforløb, benefits are paid at the level of social assistance, so for younger claimants payment rates may be relatively low, and below the rate of unemployment benefit. In principle, ressourceforløb is intended to offer integrated support coordinated across the employment, education, social work and health sectors, with interventions lasting from one to five years. The Danish Government has also pointed to substantial investments in rehabilitation provision targeting the under-40s (Brix Pedersen 2013). However, take-up of ressourceforløb has been relatively low, suggesting that the promise of coordinated, holistic services has proved difficult to deliver for local authorities, which are responsible for the implementation of these and other working age activation services. There also remain concerns that the rehabilitation plans offered to younger claimants have not been fully resourced, increasing the risk of economic insecurity faced by young people with disabilities, while intensifying the pressure upon 
JWST632-co1 JWST632-Lindsay Printer:Yet to Come July 20, 2015 8:44 Trim: 229mm $\times 152 \mathrm{~mm}$

Colin Lindsay, Bent Greve, Ignazio Cabras, Nick Ellison and Stephen Kellett

them to engage in activity that may be inappropriate and beyond their capabilities.

A second distinctive strand of active measures for people with health and disability-related limitations is the 'flex-job' programme, which provides a substantial employer subsidy for workplaces supporting those with disabilities to stay in work (and which initially offered individual participants the equivalent of a full-time wage despite working reduced hours in most cases) (Etherington and Ingold 2012). Changes introduced in 2012 reduced the work-related income received by participants, which now reflects the hours of work actually performed, with a further supplementary benefit paid at a level close to the unemployment benefit level provided to top up income. While this change has the potential to expand the reach of flex-jobs for people working fewer hours, the income received by many participants will be reduced. These changes reflect concerns among policymakers as to the affordability of the flex-jobs programme, which saw a rapid expansion in take-up during the 200os. More generally, while there are clearly attractive features associated with a flex-jobs programme that prioritizes helping people to manage conditions in the workplace (and which supports employers to make adjustments), there remain concerns that its subsidy element is seen as an 'easy option', detracting from efforts to place sick and disabled people in the unsubsidized, mainstream labour market (Etherington and Ingold 2012).

A range of more recent strategies have seen an emphasis on workfirst activation, partly facilitated by the transfer of responsibility for the delivery of much of the employability policy agenda to local government. The result has been a:

wave of management and governance reforms designed to advance a work-first agenda... [including] New Public Management reforms at the municipal level, using financial incentives and performance management to encourage implementation practices emphasizing a stronger work-first approach (Larsen 2013: 109)

In common with the $\mathrm{UK}$, there is also a reluctance among policymakers to acknowledge the importance of demand-side labour market factors in shaping DB claiming, perhaps suggesting that there are 'growing similarities in the policy discourses around activation' in Denmark and the UK (Etherington and Ingold 2012: 31).

Accordingly, despite successive governments' rhetoric around providing holistic and client-centred support for people on DBs, the take-up of services such as ressourceforløb has been low, while eligibility conditions and generosity of benefits are now less favourable for (especially younger) disability claimants. Similarly, the flex-jobs programme seems to reflect the need for workplace-rooted approaches to condition management identified in our discussion of the UK problem above, but also highlights the limitations of initiatives that rely too heavily on wage 
JWST632-co1 JWST632-Lindsay Printer:Yet to Come July 20, 2015 8:44 Trim: 229mm $\times 152 \mathrm{~mm}$

Assessing the Evidence Base on Health, Employability and the Labour Market

subsidization to create parallel labour market conditions for people with health and disability-related limitations. Danish policymakers' declared ambition to increase participation rates among the disabled has not been realized - indeed, since 2010 there has been a drop in labour market participation, especially among those with more significant disabilities (Kjeldsen et al. 2013). In common with other countries, including the UK, participation rates seem more responsive to labour demand fluctuations than to any specific policy targeting people with health and disability-related limitations (Grammenos 2011 ).

\section{Discussion and Conclusions}

Our review above confirms a disconnect between the evidence on the nature of the DBs 'problem' and an increasingly narrow and behaviourist policy agenda implemented under successive UK governments. Policymakers have presented high numbers of people on $\mathrm{DB}$ as a problem of attitude and behaviours, leading to the logical conclusion of increasing conditionality in the benefits system and compulsory activation. Our review of the evidence points to a different and much messier reality. People trapped on DBs for long periods often face substantial health problems and disability-related limitations, which explain why they left the workplace, shape attitudes towards work, and influence trajectories in and out of the labour market. Many of the same people also report employability-related barriers, ranging from gaps in basic skills to isolation from vital social networks. And crucially, the geography of labour markets defines the opportunities open to DB claimants facing a combination of health and employability-related barriers. This disadvantage is accentuated in any post-industrial local labour market where jobs are characterized by casualization, insecurity, low-pay and work intensification.

The preceding literature and evidence review can be seen as largely confirmatory, adding to the analyses presented in previous multisourced reviews of research (Beatty et al. 2009; Bambra 2011; Lindsay and Houston 2011, 2013). However, while our discussion specifically draws upon and confirms the analysis provided by, for example, Lindsay and Houston (2013), there are areas where this article - and much of the evidence presented elsewhere in this Special Issue - offers new insights. First, in this article and elsewhere in this Special Issue, authors have broadened the multi-disciplinary approach to researching the nature of disability claiming and potential policy solutions. We have drawn attention to robust clinical studies that have identified both significant health barriers among those on DBs and apparent progress following well-evidenced clinical interventions. Elsewhere, we have highlighted a broader evidence base on how the workplace and labour market shape opportunities and barriers for people on DBs.

We have also sought to link this expanded discussion of the "nature of the problem' to a critical evaluation of the current UK policy agenda. We have argued that there is a disconnect between the multi-faceted 
JWST632-co1 JWST632-Lindsay Printer:Yet to Come July 20, 2015 8:44 Trim: $229 \mathrm{~mm} \times 152 \mathrm{~mm}$

Colin Lindsay, Bent Greve, Ignazio Cabras, Nick Ellison and Stephen Kellett

complexity of the DB problem and the rationale and content of policy, which is rooted in a behaviourist logic and largely relies upon a combination of increased conditionality and work-first activation. Such approaches might reduce on-flow in the short-term - it is self-evident that any determined effort to enhance regulation to restrict DB claiming will reduce the number of successful claims. But it is difficult to see how such policies have any relevance to improving the long-term employability and health (or mitigating the disability-related limitations) of people on DBs. It is therefore unsurprising that job outcomes for people on ESA have been disappointing under the Work Programme, as they were for IB claimants under PtW. It is difficult to arrive at more detailed conclusions about the efficacy of current programmes - the Work Programme's market orientation and black box funding mechanisms mean that programme content is treated as intellectual property, with no incentive to share information on 'what works' (or does not) in assisting people on DBs (Ceolta-Smith et al. 2015). Meanwhile, recent gradual reductions in ESA numbers are likely to be the result of measures to restrict access and increase means-testing, rather than positive outcomes from activation measures such as the Work Programme. While those denied benefits may "not be on ESA in the future, they may not be in employment either' (Lindsay and Houston 2011: 714); and restrictions to DBs combined with other welfare retrenchment policies have clearly caused considerable hardship (Beatty and Fothergill 2015).

We have also seen that alternative policy approaches are possible, but that the UK is not alone in struggling to identify solutions. Denmark has grappled with its own DB problem, but has adopted very different policy responses, rooted in joined-up models of activation and collaboration with employers to facilitate adjustments in the workplace. There are principles in the Danish model - especially the engagement of employers as full partners in assisting people to cope with their conditions - that would appear to be of value in the UK context. However, the continuing high levels of disability claiming in parts of Denmark highlight the limitations of any supply-side policy in addressing the complex combination of issues that trap people on benefits for long periods.

A number of lessons for policy are discernable from the preceding discussion. If individuals are to be assisted into sustainable employment (rather than merely being prevented from claiming DBs) there is a need for well-funded, targeted activation that is flexible enough to deal with the range of employability-related barriers faced by people on DBs. Arriving at a more holistic, evidence-based approach to addressing employability-related barriers will need policymakers to grow out of their fixation with narrow, behaviourist approaches to 'incentivizing' claimants. Meanwhile, current policies to limit benefit uprating and increase the reach of means-testing are less likely to incentivize jobseeking than to increase the risk of poverty among claimants (Beatty and Fothergill 2015) and so further undermine their employability.

People claiming DBs face a range of health and disability-related barriers, which vary in their complexity and severity. Accordingly, there is a 
JWST632-co 1 JWST632-Lindsay Printer:Yet to Come July 20, $2015 \quad 8: 44 \quad$ Trim: $229 \mathrm{~mm} \times 15^{2 \mathrm{~mm}}$

Assessing the Evidence Base on Health, Employability and the Labour Market

need to retain a system that separates out a 'work-related activity group' who can be helped towards a return to work, from those facing the most severe barriers. The establishment of this distinction under ESA was positive in this respect, but there is a need for more sophisticated tools to measure both barriers and work capabilities. Better quality capability measurement can help to inform both health-focused condition management programmes and workplace adjustments that will be needed if we are to assist people to move from welfare to work. Clearly, any assessment of work capacity needs to be based on robust clinical measurement rather than pre-set government targets for removing people from benefits (Harris and Rahilly 2011 ). Most importantly, policymakers must accept that the vast majority of DB claimants face health and disability-related barriers, and that condition management and occupational health services will be an essential element in helping people to cope with these limitations in the workplace. Condition management interventions piloted under $\mathrm{PtW}$ produced mixed outcomes (like most other health services dealing with diverse client groups), but elsewhere in this Special Issue it is argued that the further testing and development of such services may have the potential to contribute to improved employability and health provision (Purdie and Kellett 2015).

There is also a need for such health and employability provision to be joined-up with policies to address the labour market and workplace aspects of the DB problem. Inequalities in the quality and availability of work are crucial to explaining the concentration of DB claiming in postindustrial regions. Demand-side interventions that promote jobs growth will therefore be required to address these inequalities. A further contribution of this article, and others in this Special Issue, is to emphasize the need for workplace interventions. Too many of the jobs that are seen as appropriate destinations for people leaving DBs are in fact defined by content and conditions that are unconducive to managing health and disability-related limitations at work. There is a need for a renewed partnership between the state and employers: the state should incentivize adjustments to the work environment and job content that might facilitate returns-to-work for people on DBs; employers need to play a proactive role in identifying potential adjustments and creating a management culture that assists the reintegration of those managing health conditions or disabilities. The retention of activation targeting a distinctive work-related activity group can only be justified if policy also addresses workplace barriers and engages employers as key partners in delivering opportunity. These relatively modest policy prescriptions to some extent reflect the analysis of advocates of a 'social model of disability', who argue that social, economic and workplace institutions explain the disadvantage of people experiencing a range of health problems and disabilities (Patrick 2012). From this perspective, policy solutions must seek the transformation of these disabling institutions, rather than targeting the supposed failings of the individual.

Some may claim that placing condition management and adjustments in the workplace at the heart of policy solutions makes unrealistic 
JWST632-co1 JWST632-Lindsay Printer:Yet to Come July 20, 2015 8:44 Trim: 229mm $\times 152 \mathrm{~mm}$

Colin Lindsay, Bent Greve, Ignazio Cabras, Nick Ellison and Stephen Kellett

demands of employers. But the regional variations in DB numbers are partly explained by the manner in which recruiters in tight labour markets are already making informal adjustments to their expectations and job demands. In 'full employment' regions, employers are more likely to recruit people with health or disability-related barriers given the absence of 'slack' in local labour markets (i.e. where nobody else is available, employers are forced to adjust their demands to facilitate the employment of people with health conditions or disabilities). Policymakers should engage with employers to formalize and transfer a culture of flexibility and adjustment across all labour markets and workplaces.

None of the critics of current policy advocates doing nothing to activate those on DBs who could potentially return to work. For Bambra and Smith (2010: 76) 'more passive approaches have often exacerbated the labour market exclusion experienced by people with a disability or chronic illness'. Similarly, Beatty et al. (2009: 718) criticize the policy inertia of the 1980 ond 1990 s that saw all stakeholders 'turn a blind eye to the scale of the issue'. There is a clear need for policy action. Increasing conditionality and means-testing, and compelling DB claimants to participate in work-first activation, may discourage some from claiming benefits - the 'deterrence effect' often celebrated by work-first advocates (for a discussion, see Daguerre and Etherington 2009) - but these measures are unlikely to produce long-term improvements in employability or health. We believe that our review of evidence above, lessons from countries like Denmark, and the findings of research presented elsewhere in this Special Issue, point to the need for a different approach. A renewed commitment to evidence-based policy in this area would produce holistic strategies to address health, employability and labour market-related barriers - the complex and inter-connected factors that explain why too many people in the UK remain trapped on long-term DBs.

\section{Note}

1. Throughout this article 'disability benefits' is used as a generic term to cover the main long-term disability/sickness/'incapacity benefits' claimed by people of working age - previously Incapacity Benefit, Income Support, and the new Employment and Support Allowance introduced from 2008.

\section{References}

Bambra, C. (201 1), Work, Worklessness and the Political Economy of Health, Oxford: Oxford University Press.

Bambra, C. and Smith, K. (2010), No longer deserving? Sickness benefit reform and the politics of (ill) health, Critical Public Health, 20, 1: 71-83.

Baumberg, B. (2014), Fit-for-work - or work fit for disabled people? The role of changing job demands and control in incapacity claims, Journal of Social Policy, 43, 2: 289-310. 
Baumberg, B. (2015), From impairment to incapacity - educational inequalities in disabled people's ability to work, Social Policy $\mathcal{E}$ Administration, 49, 2: 182-98.

Barnes, H. and Sissons, P. (2013), Redefining fit for work: welfare reform and the introduction of the Employment Support Allowance. In C. Lindsay and D. Houston (eds), Disability Benefits, Welfare Reform and Employment Policy, Basingstoke: Palgrave Macmillan, pp. 72-93.

Beatty, C. and Fothergill, S. (1994), Registered and hidden unemployment in areas of chronic industrial decline: the case of the UK coalfields. In S. Hardy, G. Lloyd and I. Cundell (eds), Tackling Unemployment and Social Exclusion: Problems for Regions, Solutions for People, London: Regional Studies Association, pp. $38-48$.

Beatty, C. and Fothergill, S. (2015), Disability benefits in an era of austerity, Social Policy Eं Administration, 49, 2: 161-81.

Beatty, C., Fothergill, S. and Houston, D. (2013), The impact of the UK's disability benefit reforms. In C. Lindsay and D. Houston (eds), Disability Benefits, Welfare Reform and Employment Policy, Basingstoke: Palgrave Macmillan, pp. $134-52$.

Beatty, C., Fothergill, S. and Macmillan, R. (2000), A theory of employment, unemployment and sickness, Regional Studies, 34, 7: 61 7-30.

Beatty, C., Fothergill, S., Houston, D., Powell, R. and Sissons, P. (2009), A gendered theory of employment, unemployment and sickness, Environment and Planning C: Government and Policy, 27, 6: 958-74.

Beatty, C., Fothergill, S., Houston, D., Powell, R. and Sissons, P. (2010), Bringing Incapacity Benefit numbers down: to what extent do women need a different approach? Policy Studies, 31, 2: 143-62.

Brix Pedersen, K. (2013), Replacing Disability Pension for Young People Under 40 with a Rehabilitation Model, Paper given at the OECD Mental Health and Work Seminar, OECD Headquarters, Paris, France, 17 April.

Carter, B., Danford, A., Howcroft, D., Richardson, H., Smith, A. and Taylor, P. (2013), Stressed out of my box: employee experiences of lean working and occupational ill-health in clerical work in the UK public sector, Work, Employment $\mathcal{E}^{\circ}$ Society, 27, 5: 747-67.

Centre for Social Justice (CSJ) (2009), Dynamic Benefits, London: CSJ.

Ceolta-Smith, J., Salway, S. and Tod, A. $(2015)$, A review of health-related support provision within the UK Work Programme - what's on the menu? Social Policy Eं Administration, 49, 2: 254-76.

Daguerre, A. with Etherington, D. (2009), Active Labour Market Policies in International Context: What Works Best? Lessons for the UK, London: Department for Work and Pensions.

Department for Work and Pensions (DWP) (2010), 2 Ist Century Welfare, London: Department for Work and Pensions.

Dixon, J. and Warrener, M. (2008), Pathways to Work: Qualitative Study of In-Work Support, DWP Research Report No. 478, Leeds: Corporate Document Services.

Easterlow, D. and Smith, S. J. (2003), Health and employment: towards a New Deal, Policy and Politics, 31, 4: $5^{1} 1-33$.

Etherington, D. and Ingold, J. (2012), Welfare to work and the inclusive labour market: a comparative study of activation policies for sickness benefit claimants in the UK and Denmark, Journal of European Social Policy, 22, 1: 30-44.

Garthwaite, K. (2015), 'Keeping meself to meself' - how social networks can influence narratives of stigma and identity for long-term sickness benefits recipients, Social Policy E Administration, 49, 2: 199-212. 
JWST632-co 1 JWST632-Lindsay Printer:Yet to Come July 20, 2015 8:44 Trim: $229 \mathrm{~mm} \times 152 \mathrm{~mm}$

Colin Lindsay, Bent Greve, Ignazio Cabras, Nick Ellison and Stephen Kellett

Garthwaite, K., Bambra, C., Warren, J., Kasim, A. and Greig, G. (2014), Shifting the goalposts: a longitudinal mixed-methods study of the health of long-term Incapacity Benefit Recipients during a period of substantial change to the UK social security system, Journal of Social Policy, 43, 2: 311-30.

Grammenos, S. (201 1), Indicators of Disability Equality in Europe, Leeds: Academic Network of European Disability Experts.

Grant, A. (2013), Welfare reform, conditionality and targets: Jobcentre Plus advisers' experiences of targets and sanctions, Journal of Poverty and Social Justice, $21,2: 16_{5}-76$.

Green, A. (1994), The changing structure, distribution and spatial segregation of the unemployed and economically inactive in Great Britain, Geoforum, 26, 4: $373-94$.

Green, A. and Shuttleworth, I. (2010), Local differences, perceptions and incapacity benefit claimants: implications for policy delivery, Policy Studies, 31, 2: $223-43$.

Green, A. and Shuttleworth, I. (2013), Are incapacity benefit claimants beyond employment? Exploring issues of employability. In C. Lindsay and D. Houston (eds), Disability Benefits, Welfare Reform and Employment Policy, Basingstoke: Palgrave Macmillan, pp. 54-71.

Harrington, M. (2010), An Independent Review of the Work Capability Assessment, London: Stationery Office.

Harris, N. and Rahilly, S. (2011), Extra capacity in the labour market? ESA and activation for the sick and disabled in the UK. In S. Devetzi and S. Stendahl (eds), Too Sick to Work?, Alphen aan den Rijn: Kluwer, pp. 43-75.

House of Commons Work and Pensions Committee (HoC) (2013), Can the Work Programme Work for All User Groups? Report HCI 62, London: The Stationery Office.

Jones, A., Rice, N. and Roberts, J. (2010), Sick of work or too sick to work? Evidence on self-reported health shocks and early retirement from the BHPS, Economic Modelling, 27: 866-8o.

Kellett, S., Bickerstaff, D., Purdie, F., Dyke, A., Filer, S., Lomax, V. and Tomlinson, H. (2011), The clinical and occupational effectiveness of condition management for Incapacity Benefit recipients, British Journal of Clinical Psychology, 50, 2: 164-77.

Kemp, P. A. and Davidson, J. (2009), Gender differences among new claimants of Incapacity Benefit, Journal of Social Policy, 38, 4: 589-6o6.

Kemp, P. A. and Davidson, J. (2010), Employability trajectories among new claimants of Incapacity Benefit, Policy Studies, 31, 2: 203-2 1.

Kjeldsen, M., Houlberg, H. and Hodelund, J. (2013), Handicap og Beskaftigelse. Udviklingen Mellem 2002 og 201 2, Copenhagen: The Danish National Centre for Social Research.

Larsen, F. (2013), Active labour market reform in Denmark: the role of governance in policy change. In E. Z. Brodkin and G. Marston (eds), Work and the Welfare State: Street-level Organizations and Workfare Politics, Copenhagen: DJOF.

Lindsay, C. and Dutton, M. (2013), Promoting healthy routes to employability: lessons for welfare-to-work in the UK, Policy and Politics, 41, 2: $183-$ 200.

Lindsay, C. and Houston, D. (201 1), Fit for purpose? Welfare reform and challenges for health and labour market policy in the UK, Environment and Planning $A, 43,3: 703-21$.

Lindsay, C. and Houston, D. (2013), Disability Benefits, Welfare Reform and Employment Policy, Basingstoke: Palgrave Macmillan. 
JWST632-col JWST632-Lindsay Printer:Yet to Come July 20, 2015 8:44 Trim: $229 \mathrm{~mm} \times 15^{2 \mathrm{~mm}}$

Assessing the Evidence Base on Health, Employability and the Labour Market

Lindsay, C. and McQuaid, R. W. (20o9), New governance and the case of activation policies: comparing experiences in Denmark and the Netherlands, Social Policy Eं Administration, 43, 5: 445-63.

McKee-Ryan, F. M., Song, Z., Wamberg, C. R. and Kinicki, A. J. (2005), Psychological and physical well-being during unemployment: a meta-analytic study, Journal of Applied Psychology, 90, 1: 53-76.

National Audit Office (NAO) (2010), Support to Incapacity Benefits Claimants Through Pathways to Work, London: NAO.

Organisation for Economic Co-operation and Development (OECD) (2011), Sick on the Job? Myths and Realities about Mental Health at Work, Paris: OECD.

Organisation for Economic Co-operation and Development (OECD) (2013), Employment Outlook, Paris: OECD.

Patrick, R. (2012), All in it together? Disabled people, the Coalition and welfare to work, Journal of Poverty and Social Justice, 20, 3: 307-22.

Purdie, F. and Kellett, S. (2015), The influence of presenting health condition on eventual return to work for individuals receiving health-related welfare benefits, Social Policy Eं Administration, 49, 2: 236-53.

Rees, J., Whitworth, A. and Carter, E. (2014), Support for all in the UK Work Programme? Differential payments, same old problem, Social Policy E Administration, 48, 2: 221-39.

Rick, J., Carroll, C., Jagger, N. and Hillage, J. (2008), Review of the Effectiveness and Cost Effectiveness of Interventions, Strategies, Programmes and Policies to Help Recipients of Incapacity Benefits Return to Employment (Paid and Unpaid), Brighton: Institute for Employment Studies.

Robroek, S., Schuring, M., Croezen, S., Stattin, M. and Burdorf, A. (2013), Poor health, unhealthy behaviors and unfavorable work characteristics influence pathways of exit from paid employment among older workers in Europe: a four year follow-up study, Scandinavian Journal of Work and Environment Health, 39, 1: $125^{-33}$.

Shildrick, T., MacDonald, R., Webster, C. and Garthwaite, K. (2012), Poverty and Insecurity: Life in Low-pay, No-pay Britain, Bristol: Policy Press.

Taylor, P., Cunningham, I., Newsome, K. and Scholarios, D. (2010), Too scared to go sick - reformulating the research agenda on sickness absence, Industrial Relations Journal, 41, 4: 270-88.

Webster, D., Brown, J., Macdonald, E. and Turok, I. (2013), The interaction of health, labour market conditions and long-term sickness benefit claims in a post-industrial city: a Glasgow case study. In C. Lindsay and D. Houston (eds), Disability Benefits, Welfare Reform and Employment Policy, Basingstoke: Palgrave Macmillan, pp. $111-33$.

Whittaker, W. and Sutton, M. (2015), Measuring the impacts of health conditions on work incapacity - evidence from the British Household Panel Survey, Social Policy E Administration, 49, 2: 213-35. 
JWST632-co $\quad J W S T 632-L i n d s a y \quad$ Printer:Yet to Come July 20, 2015 8:44 Trim: 229mm $\times 152 \mathrm{~mm}$ 